FERMIIAB-TM-1827

\title{
Silicon Crystal Under Bending
}

\author{
Zhijing Tang \\ Fermi National Accelerator Laboratory \\ P.O. Box 500, Batavia, Illinois 60510
}

February 1993 


\section{Disclaimer}

This report was prepared as an account of work sponsored by an agency of the United States Government. Neither the United States Government nor any agency thereof, nor any of their employees, makes any warranty, express or implied, or assumes any legal liability or responsibility for the accuracy, completeness, or usefulness of any information, apparatus, product, or process disclosed, or represents that its use would not infringe privately owned rights. Reference herein to any specific commercial product, process, or service by trade name, trademark, manufacturer, or otherwise, does not necessarily constitute or imply its endorsement, recommendation, or favoring by the United States Government or any agency thereof. The views and opinions of authors expressed herein do not necessarily state or reflect those of the United States Government or any agency thereof. 
TM-1827

\title{
Silicon Crystal under Bending
}

\author{
Zhijing Tang \\ February 11, 1993
}

\begin{abstract}
The mechanical behavior of a silicon crystal under bending is investigated. For a crystal of length $30 \mathrm{~mm}$ and thickness $3 \mathrm{~mm}$, to achieve the specified bend angle of $0.64 \mathrm{mrad}$, the appropriate angle of the aluminum punches is $0.96 \mathrm{mrad}$.
\end{abstract}

\section{Introduction}

The beam channeling experiment (E853) requires to bend the silicon crystal to a certain degree. Fig. 0 is the sketch of the situation. It is desirable to know the deformation and the stress level in the crystal under bending, and to investigate the methods of achieving such bending.

The crystal is cut in the direction shown in Fig.1, and a local coordinate system is also shown in the figure; the $z$-direction is along the longest edge, and the $y$-direction is along the shortest edge.

This work used ANSYS to study the deformation and stresses in the crystal under bending. ANSYS has the orthotropic material property capability, an essential tool for the analysis of crystals. From the crystal data provided by Thornton Murphy, the following material properties are calculated: $E_{x x}$ $=1.30208 \times 10^{5} \mathrm{~N} / \mathrm{mm}^{2}, \nu_{x y}=0.278646, G_{x y}=0.39809 \times 10^{5} \mathrm{~N} / \mathrm{mm}^{2}$.

Since the problem is symmetric with respect to the plane $z=0$, only half of the crystal is modeled. The dimension of the half crystal is $15 \times 10 \times 3 \mathrm{~mm}$.

We first use a bare crystal and specify the displacement at its surfaces, to study the basic characteristics of the crystal under bending. Then crystals with different orientations are compared with each other. After that a crystal squeezed between cylindrical aluminum punches is investigated to take into account the deformation of the punches. Finally, punches with increased curvature are used to achieve the required bend angle. 


\section{Crystal under Bending}

The finite element mesh is shown in Fig.2 with a local coordinate system. These are 20-node solid elements, and each element is a $1 \mathrm{~mm}$ cube. Also in the figure we marked some points which are actually some lines parallel to the $z$-axis. Later on we will examine the deformation along these lines.

The first analysis is for a bare crystal, with the angle $\beta=0$ in Fig.1. Displacements are specified at its top and bottom surfaces. That is, ANSYS is told that the top and bottom surfaces are constrained to a cylindrical shape (for $x<8 \mathrm{~mm}$ and $z<10 \mathrm{~mm}$ ), without worrying yet about how this shape is achieved. The total bend angle at the surfaces is $0.32 \mathrm{mrad}$.

The deformed crystal is shown in Fig.3. Fig.4 shows the displacement $u_{y}$ at $A$ as a function of nodes, and Fig.5 gives the differences in $u_{y}$ between $A$ and $B$, and $A$ and $C$. Notice that the differences are two orders of magnitude smaller than the displacement itself; that means the displacement is quite uniform. Combining the previous two figures in Fig.6 shows this result where the difference is unnoticeable. Fig. 7 shows the displacement $u_{z}$ at $D$ and $E$, which shows a nice bending. And in Fig.8 is the displacement $u_{x}$ at $D$ and $E$, which shows the warping out of the bending plane.

Our main interest is in the final bend angle. Differentiating the displacement curve yields the slope, or the bend angle of the crystal. Fig.9 is the bend angle at $C, D$ and $E$; they are almost identical. Fig.10 shows the bend angle at $A, F$ and $G$. Notice the big oscillation near $Z=10 \mathrm{~mm}$ in the curves for $F$ and $G$. This is caused by the discontinuity in stress, since for $z<10 \mathrm{~mm}$ the displacement is specified, while for $z>10 \mathrm{~mm}$ the stress is free. Fig.11 compares the bend angle at $A$ and $C$. There is a little difference near $z=10 \mathrm{~mm}$, but the bend angle at the edge $z=15 \mathrm{~mm}$ is the same.

Overall, the final bend angle, i.e. the bend angle at $z=15 \mathrm{~mm}$, is only 0.27 mrads, less than the 0.32 mrads specified at the surfaces. This is due to the flap-back tendency, a tendency of the over hanging portion of the crystal, to try to counter the bending, thus causing the bend angle to decrease after entering the stress-free region. This phenomenon is very interesting as can be noted from Fig.10. The curve for $A$, which is in the middle layer of the crystal, is more smooth than the curve for $F$ and $G$, they are at surface, where displacement is specified for $z<10 \mathrm{~mm}$. 
Figs.12 and 13 give the stresses $\sigma_{y y}$ and $\sigma_{z z}$. It is seen that the maximum stress is $6.655 \mathrm{~N} / \mathrm{mm}^{2}$, much smaller than the yield stress of $100 \mathrm{~N} / \mathrm{mm}^{2}$.

We also did analysis for other cases, i.e. crystals with different orientations. The results are summarized in Table I. The results do depend on the orientation of the crystal, but the difference is not dramatic, as can be seen from Table I.

\section{Crystal between Aluminum Punches}

The next work is the crystal under compression by two half aluminum punches, prepared with the specified curvature. The crystal is as shown in Fig.1 with the angle $\beta=0$. Again the stress is moderate, but the bend angle is much less than what is expected, as shown in Figs.15 and 16. In fact, the angle is only $2 / 3$ of the required. This is due to the finite stiffness of the aluminum punches. When they are compressed against the crystal, they deform also, and thus the final curvature of the aluminum punches is less than initially specified. Furthermore, even if the final punch curvature remains unchanged, as in the previous case where displacement at the surface is prescribed, the final angle is still less than required.

To compensate for the deficiency of the bend angle, we increased the initial curvature of the aluminum punches from 0.32 mrads to 0.48 mrads. This turned out to be satisfactory. Fig. 17 gives the bend angle at $C, D$ and $E$, Fig.18 gives bend angle at $A, F$ and $G$, and Fig.19 compares the bend angle at $A, C$ and $H$.

Figs.20 and 21 give the stresses $\sigma_{y \nu}$ and $\sigma_{z z}$. The maximum bending stress is only $9.8 \mathrm{~N} / \mathrm{mm}^{2}$ or $1420 \mathrm{psi}$. No noticeable stress concentration has been found, and the maximum compressive stress is only $2.464 \mathrm{~N} / \mathrm{mm}^{2}$ or 357 psi.

The total force required to press the punch is 23.12 newton, or $2.36 \mathrm{~kg}$. Since this is a half model, the total force required to bend the crystal will be $4.72 \mathrm{~kg}$.

\section{Conclusions}


Due to the finite stiffness of the punches and the flap-back of the bent crystal, the final bend angle is less than the initial angle specified by the curvature of the punches. For the case studied, the initial angle of the aluminum punches is set to 0.48 mrads to achieve the final bend angle of the crystal, 0.32 mrads. The maximum stress in the crystal is less than $1500 \mathrm{psi}$, and the force required to bend the crystal is less than $5 \mathrm{~kg}$. 
Table I. Compure rosults for different Orientations

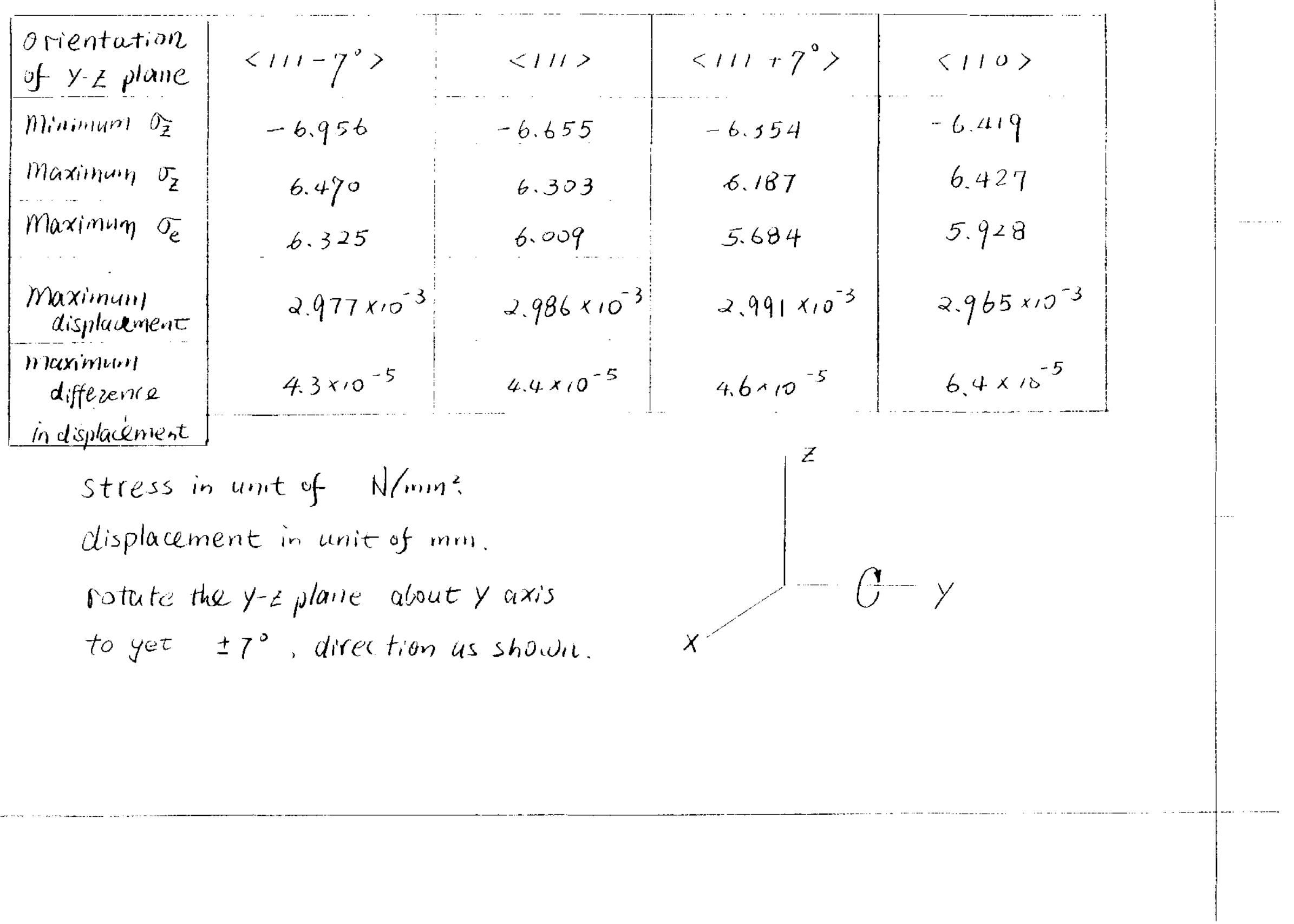




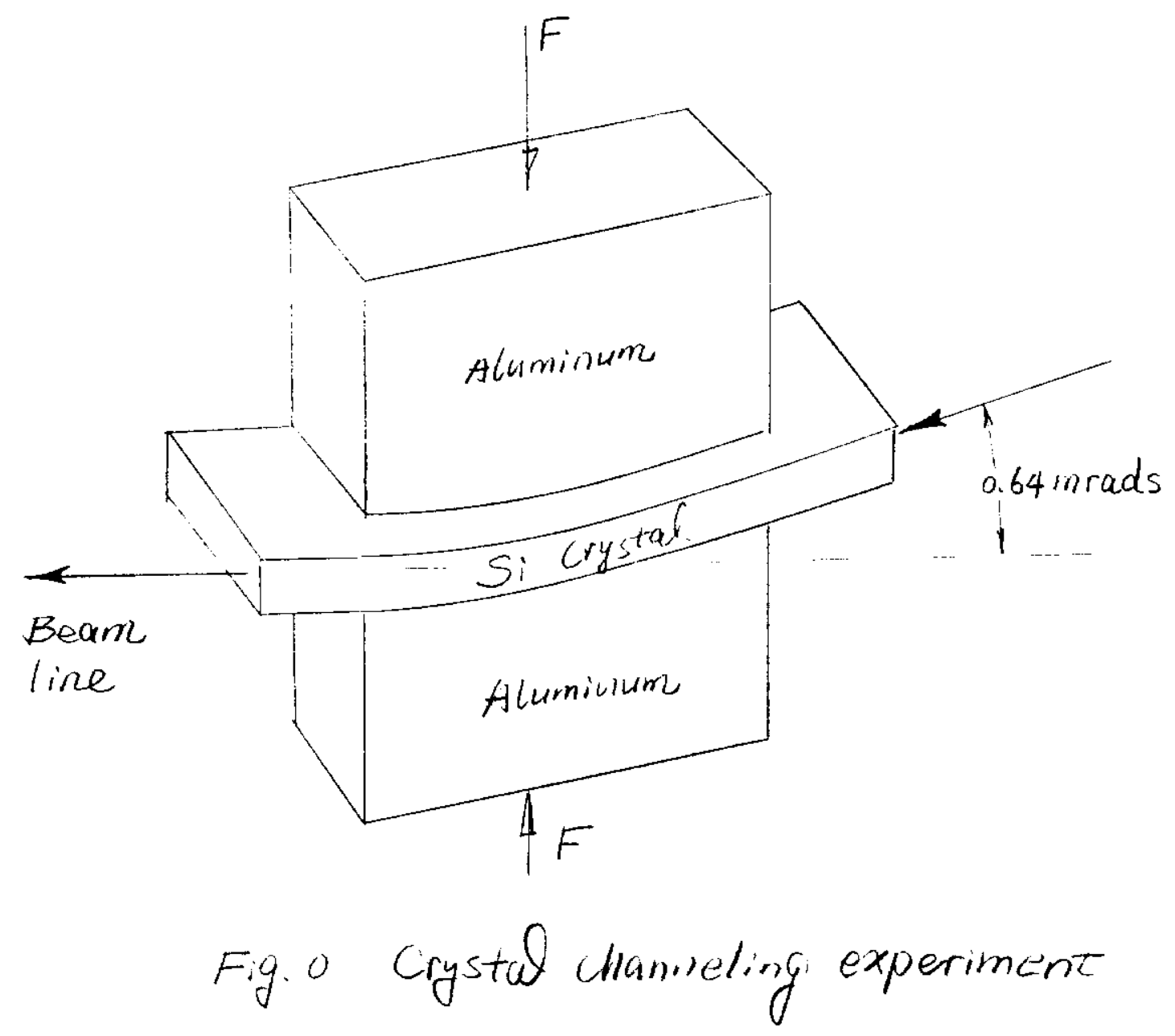




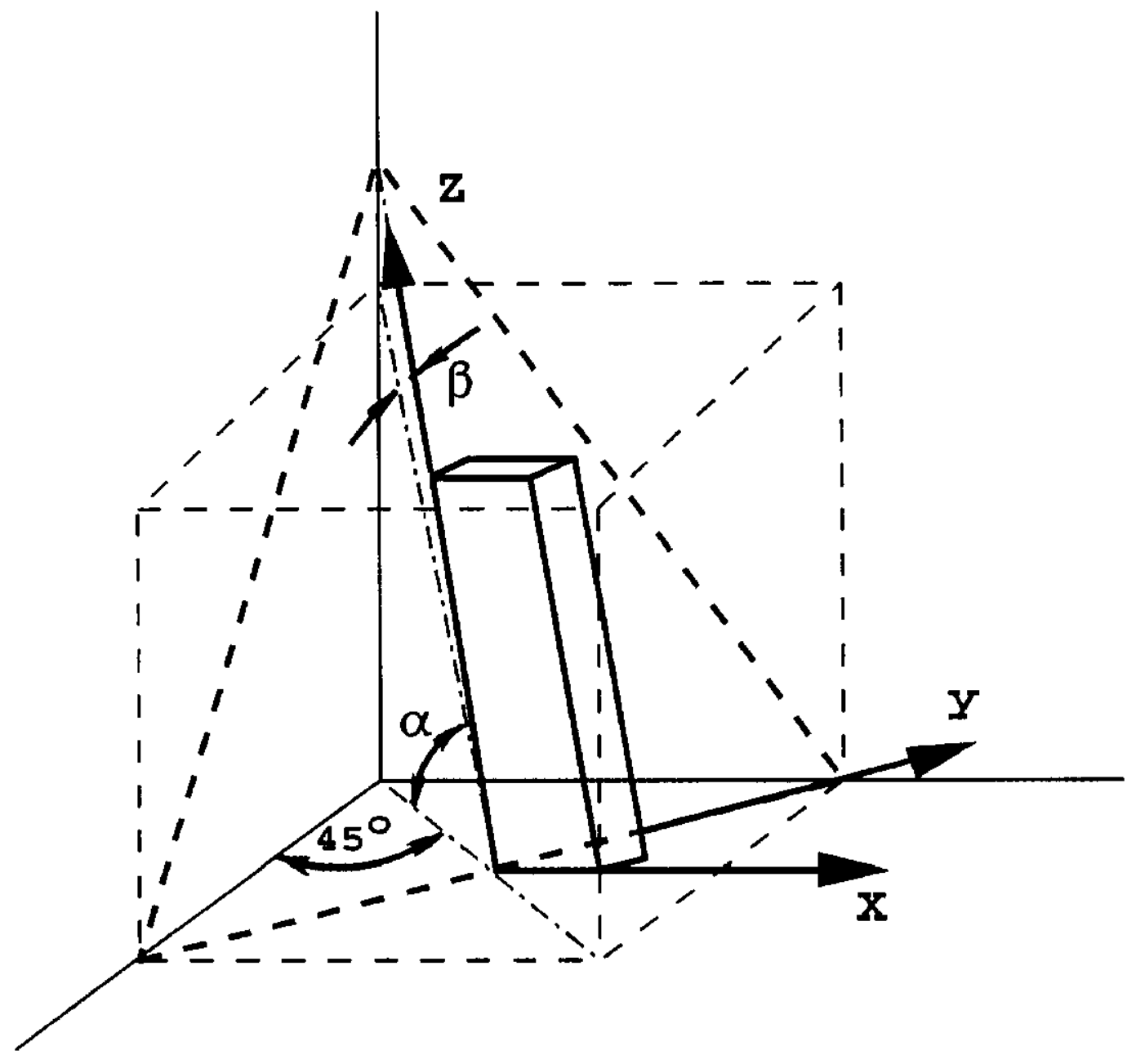

Fig.1

The orientation of the crystal

$$
\begin{aligned}
& \alpha=90-35.2644^{\circ} \\
& \beta=-7,0,+7^{\circ}
\end{aligned}
$$



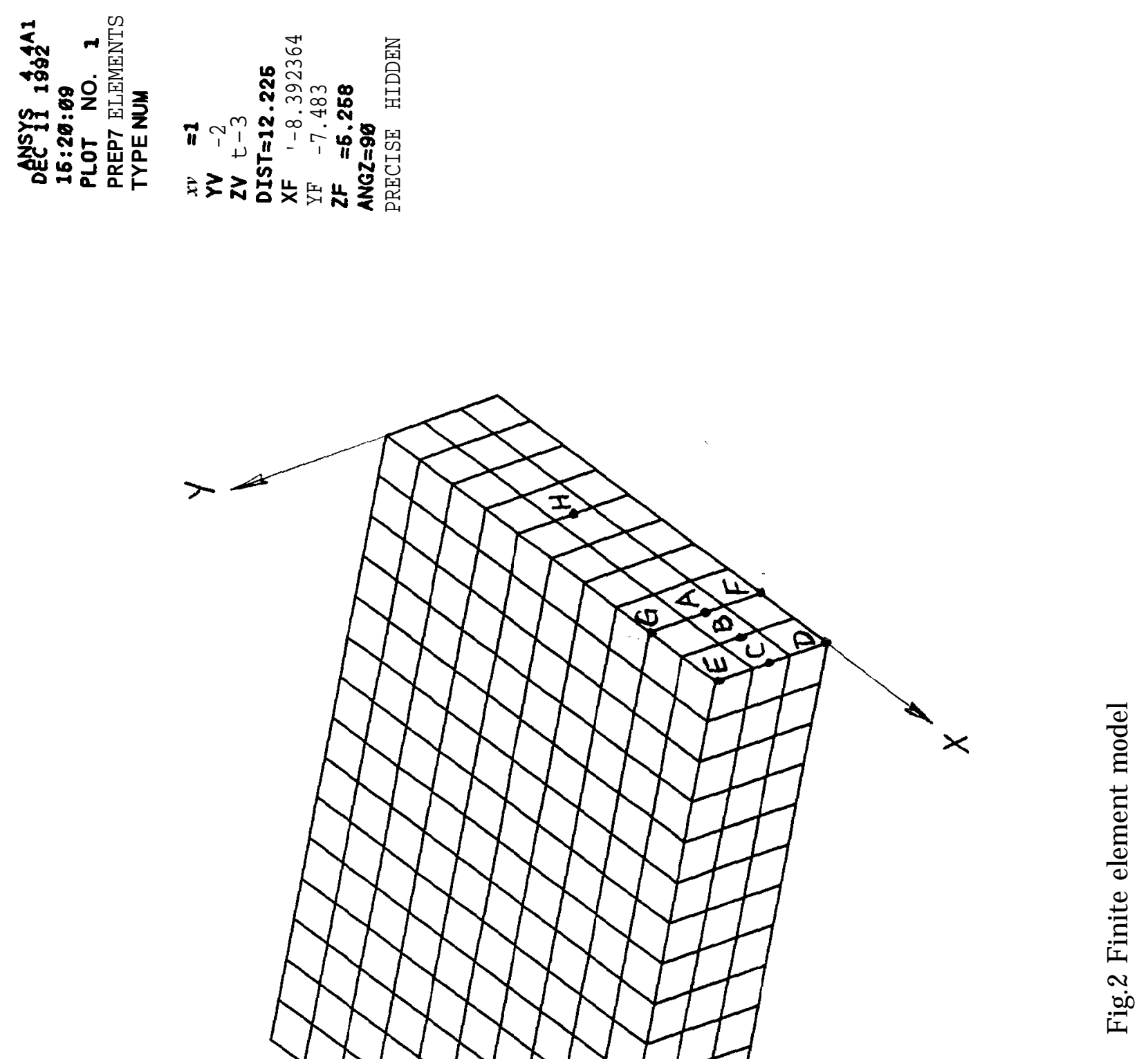


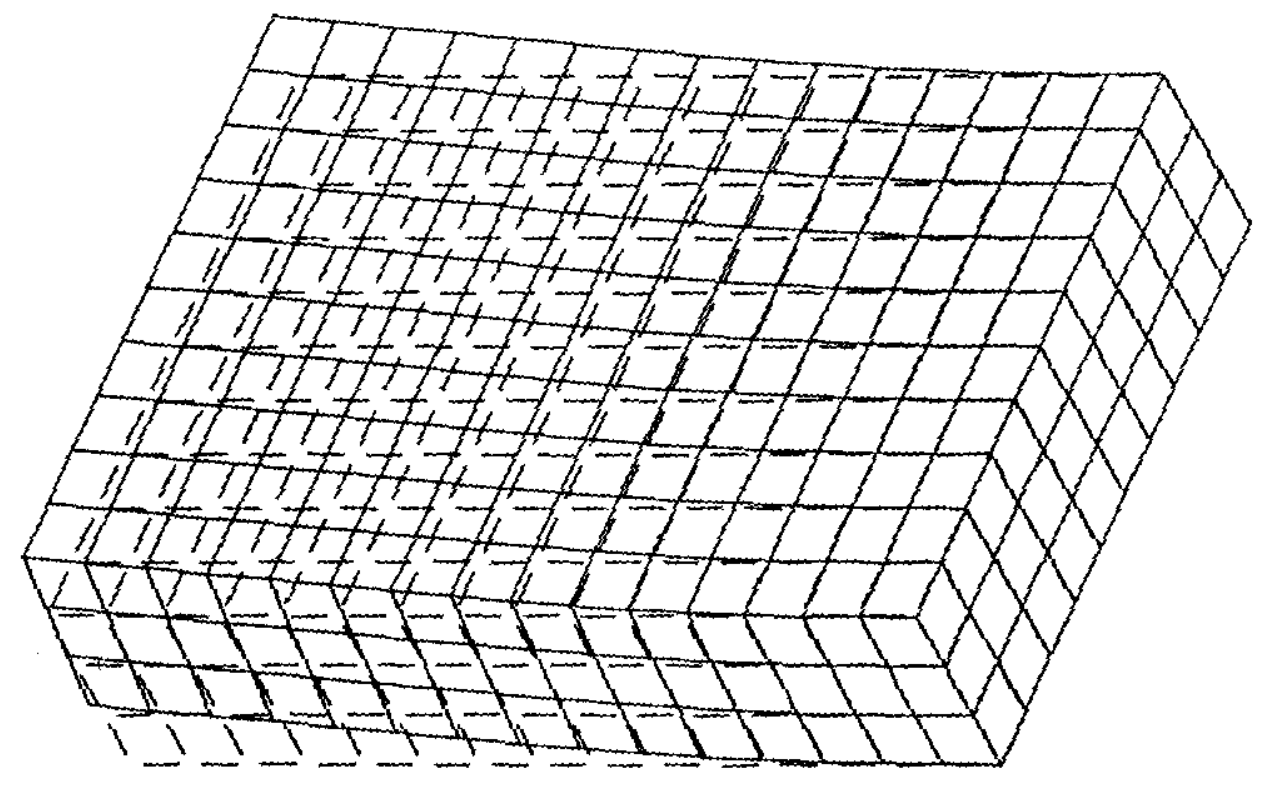

STEP $=$

ITER $=1$

002988

$\operatorname{anx}=0.00287$

$D S C A=409.431$

$X V=\frac{1}{2}$

$y V=2$

ZV $=-3$

DIST $=12.2252354$

$X F=-0.393$

$Y F=7.463$

$Z F=5.258$

ANGL $=90$ HIODEN

Fig. 3 Deformed model

Crystal 
Since the element mesh is $1 \mathrm{~mm}^{3}$ cubes, the distance along the $Z$ direction can be obtained in unit of $\mathrm{mm}$ by subtracting 1 from the node number. All the displacements are in $\mathrm{mm}$.

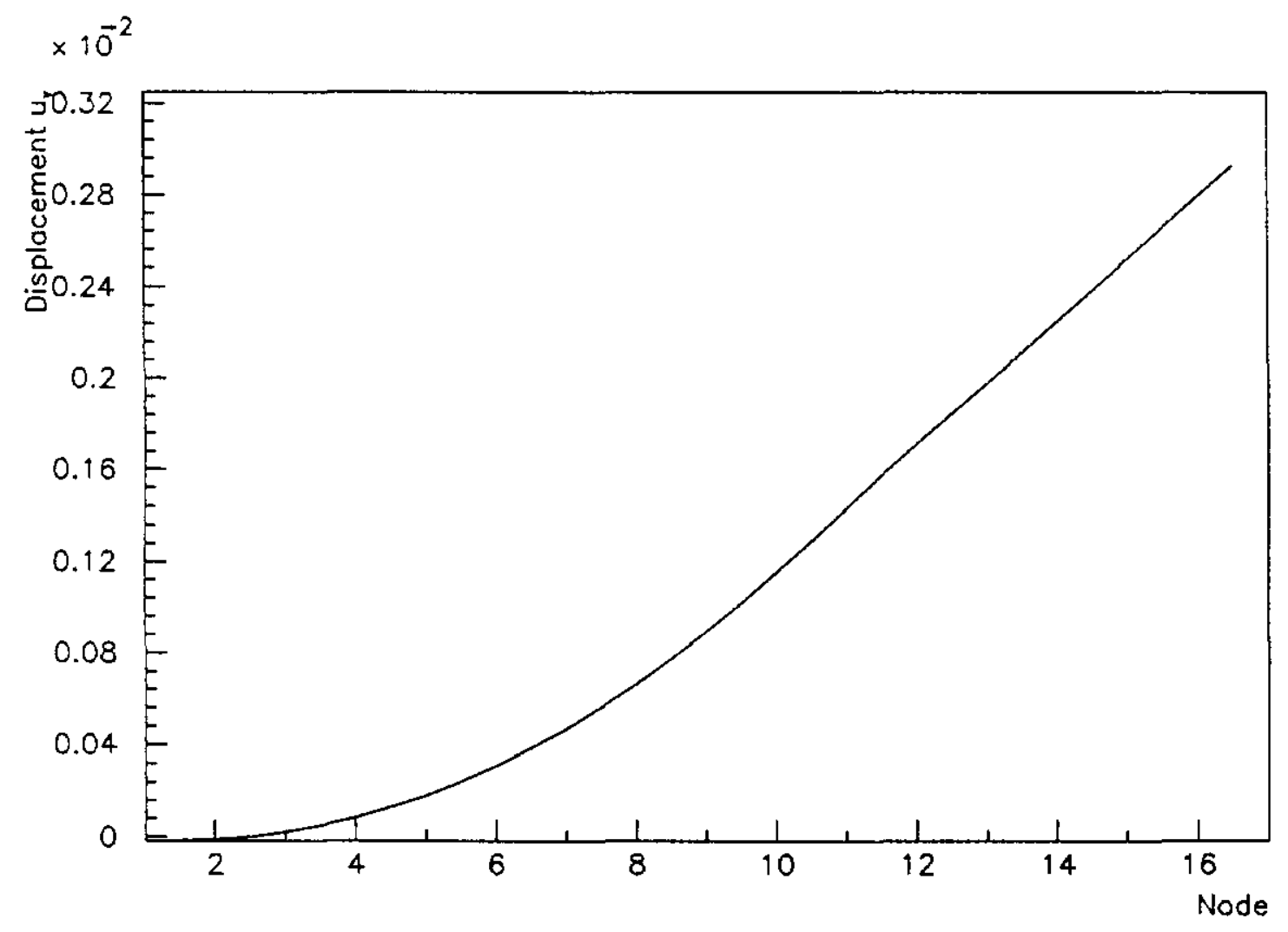

Fig.4 Displacement $u_{y}$ at point $A$ 


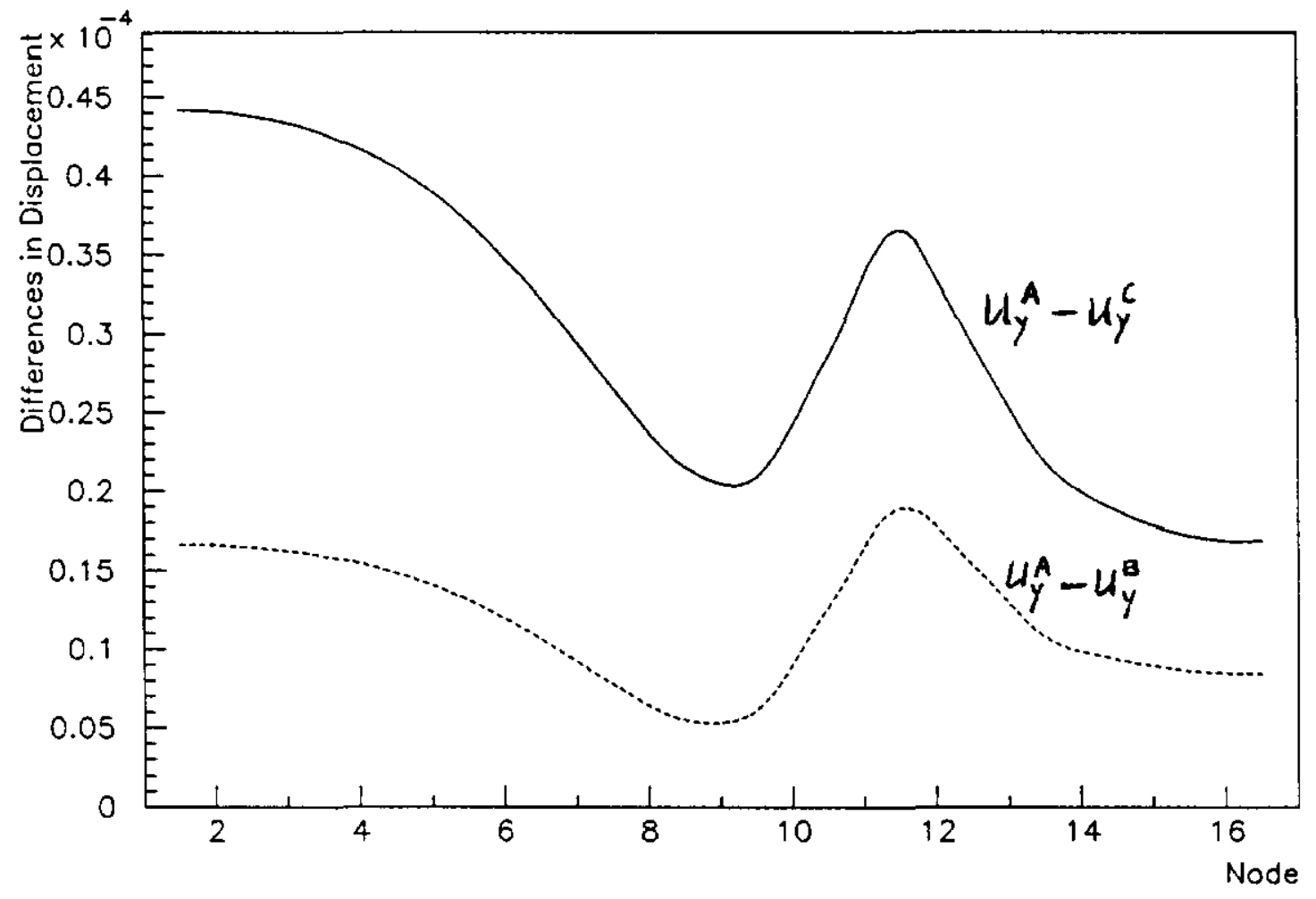

Fig.5 Differences in $u_{y}$ 


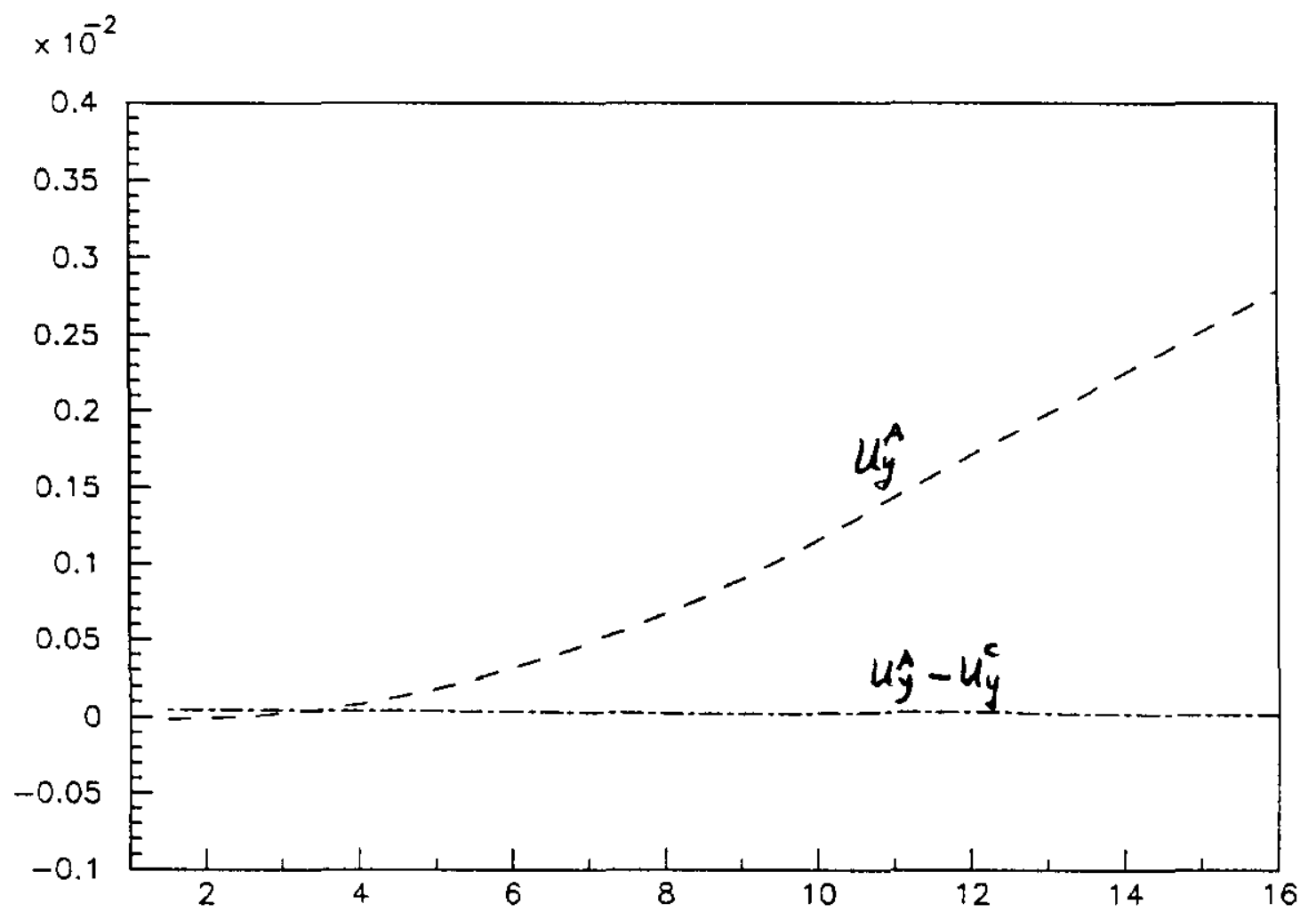

Fig.6 Difference in $u_{y}$ compared with $u_{y}$ 


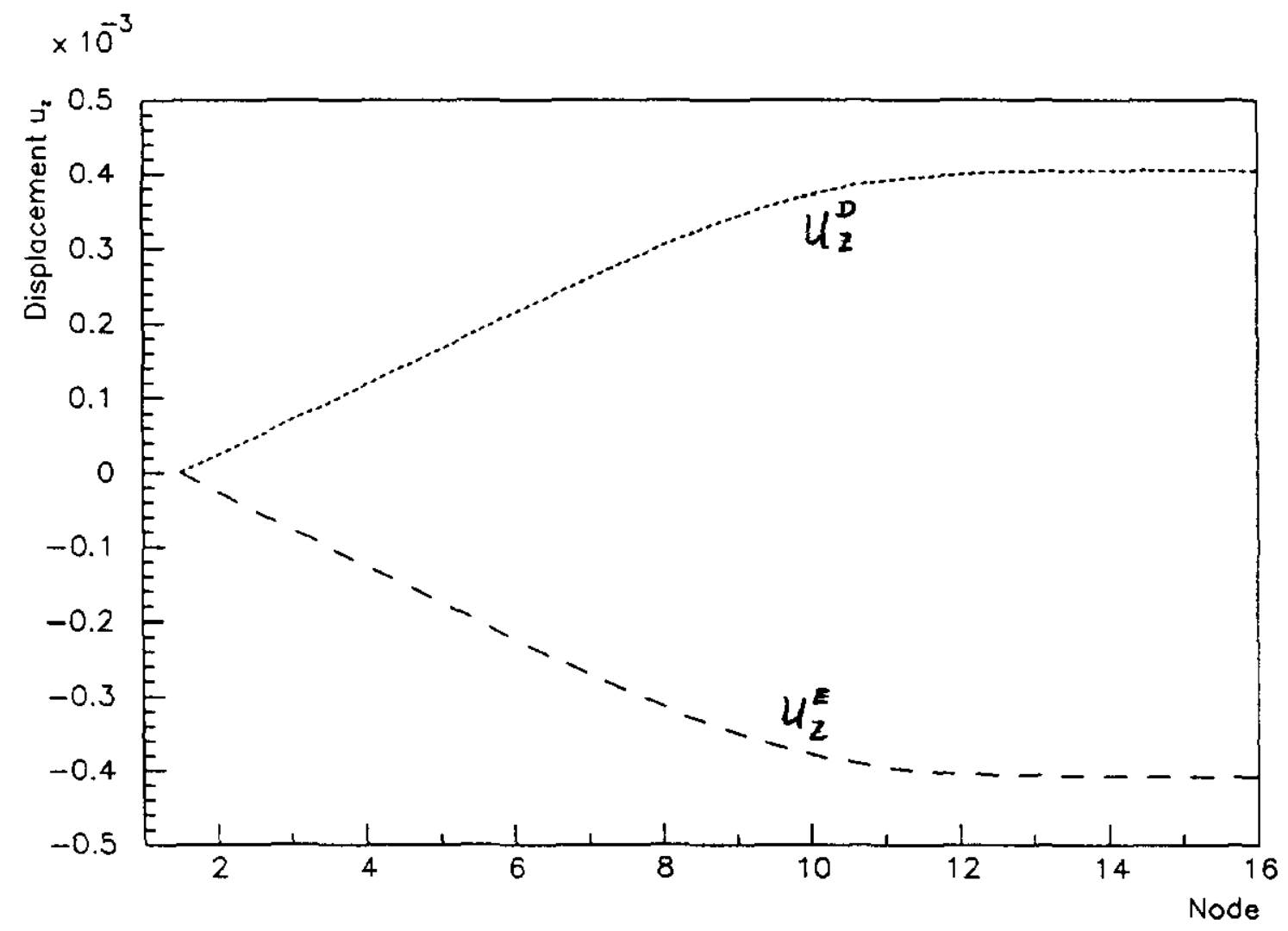

Fig.7 Displacements $u_{z}$ 


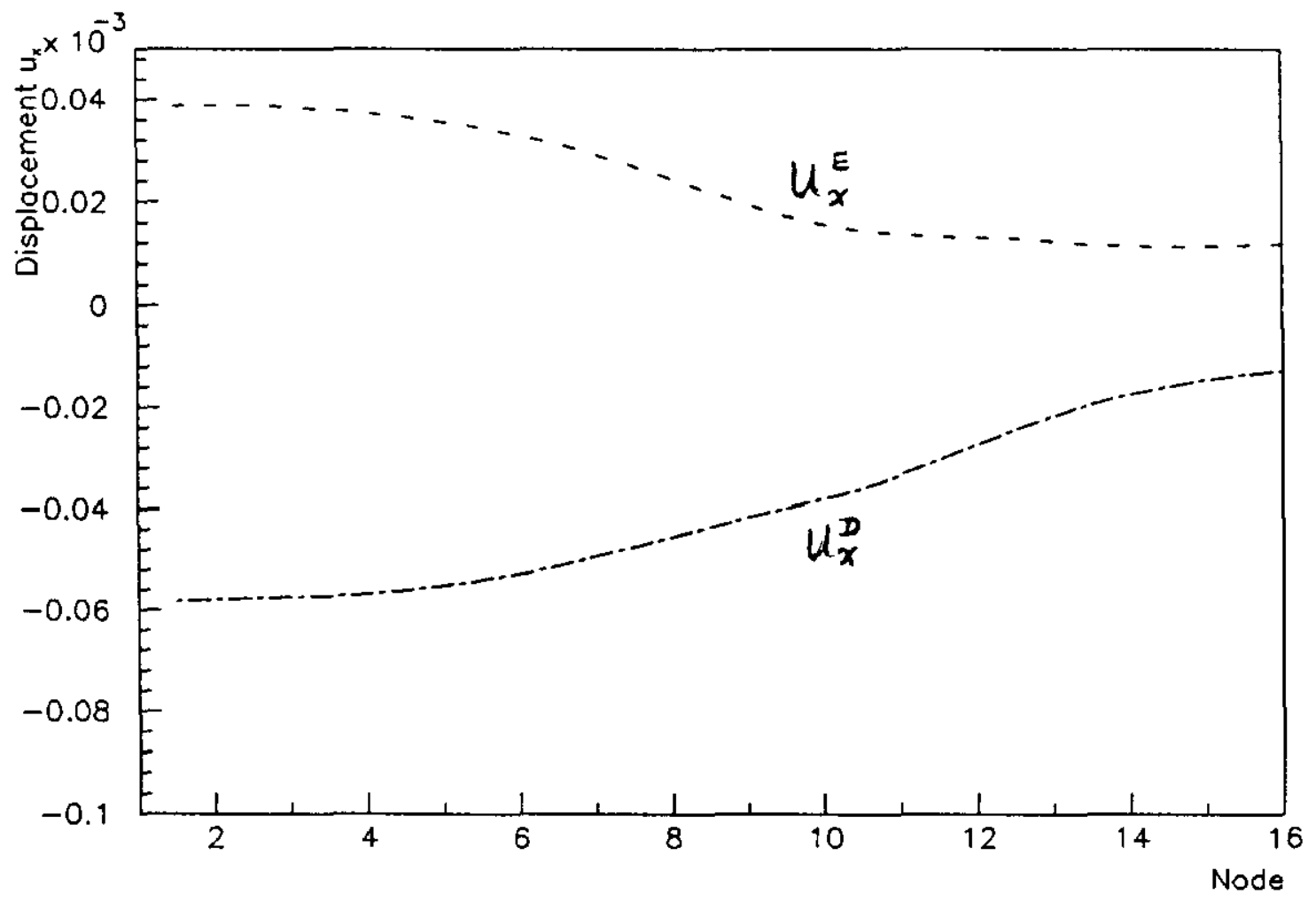

Fig.8 Displacements $u_{\text {. }}$ 


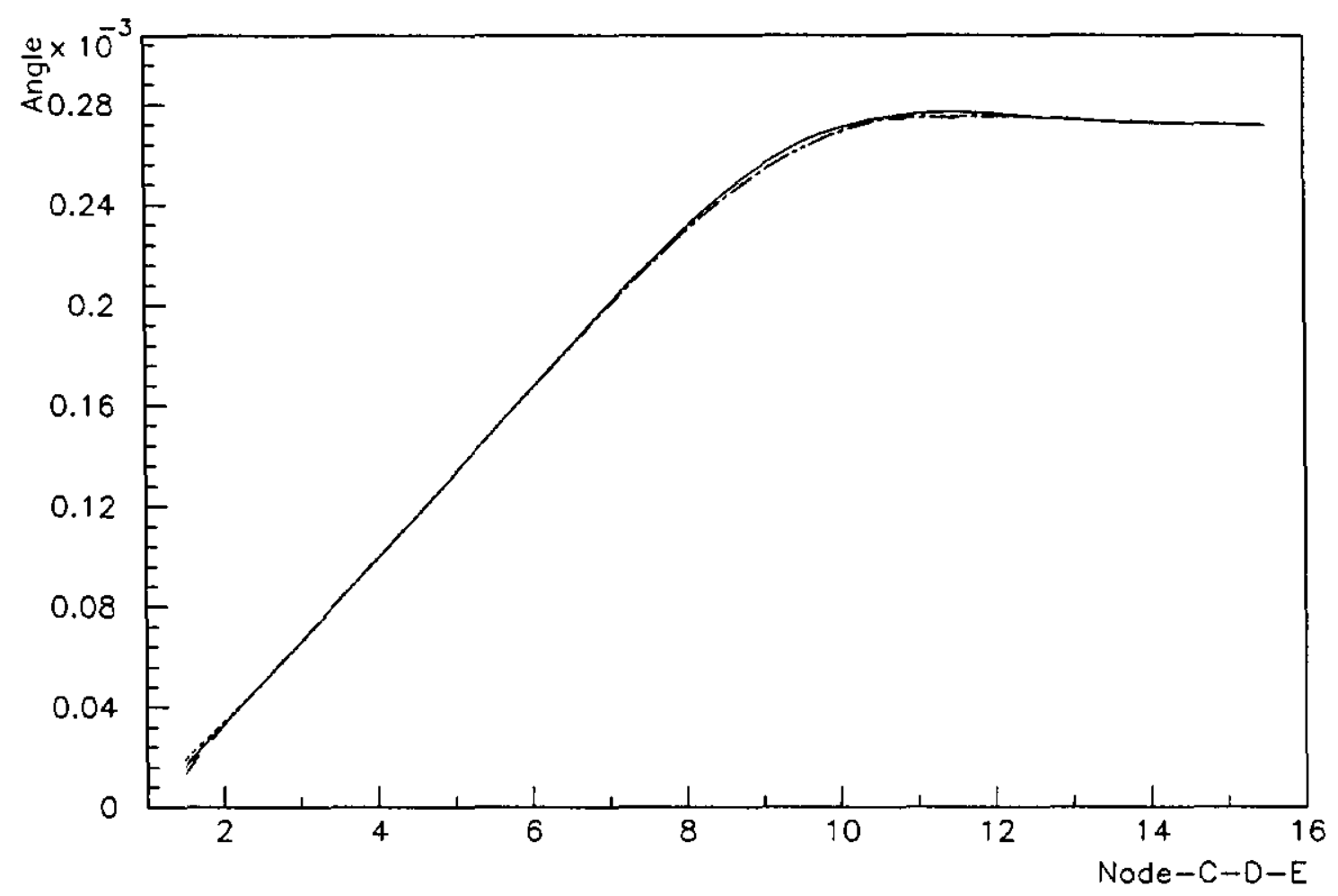

Fig.9 Bend angles at $C, D, E$ (Bare crystal) 


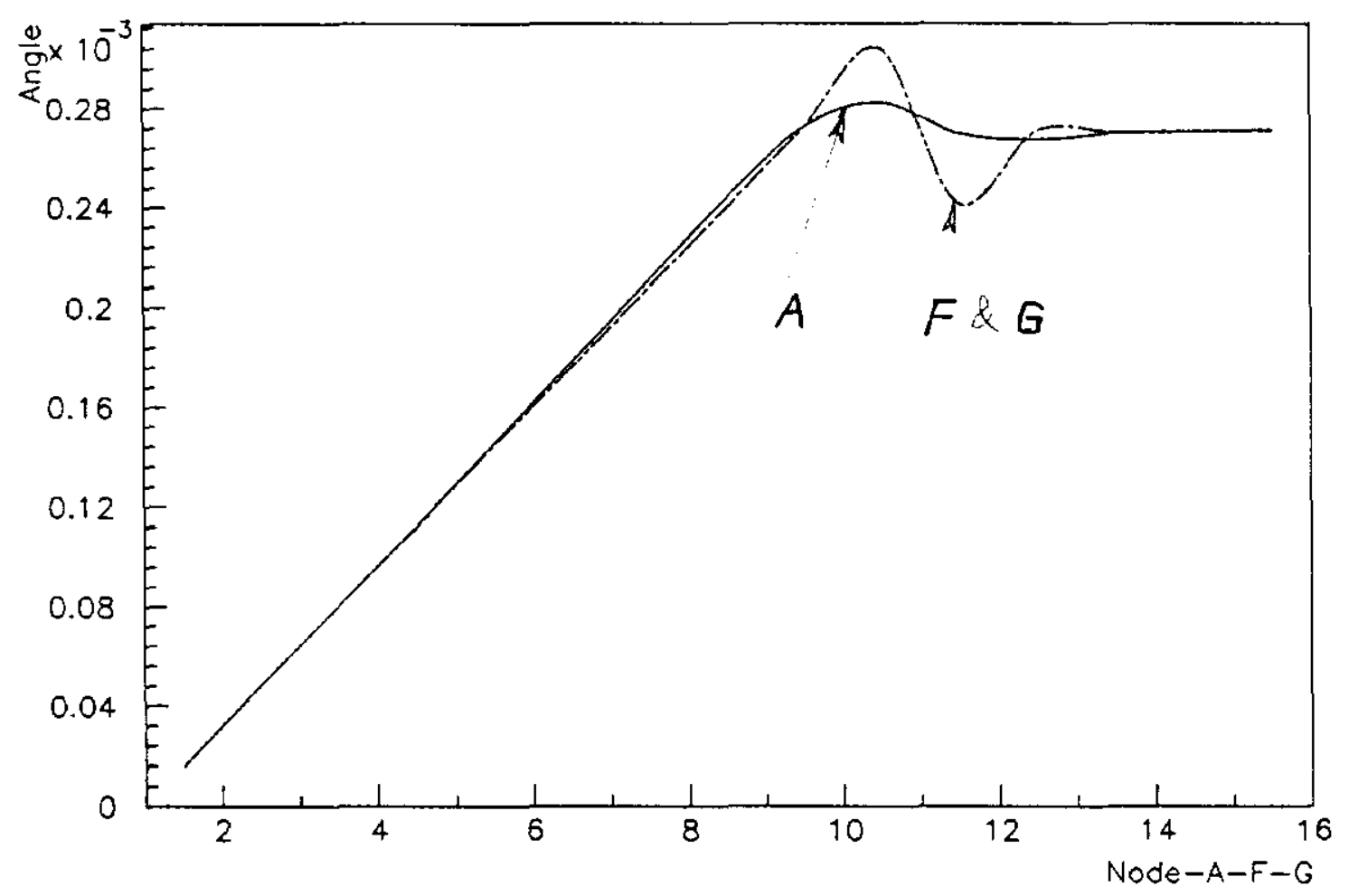

Fig.10 Bend angles at $A, F, G$ (Bare crystal) 


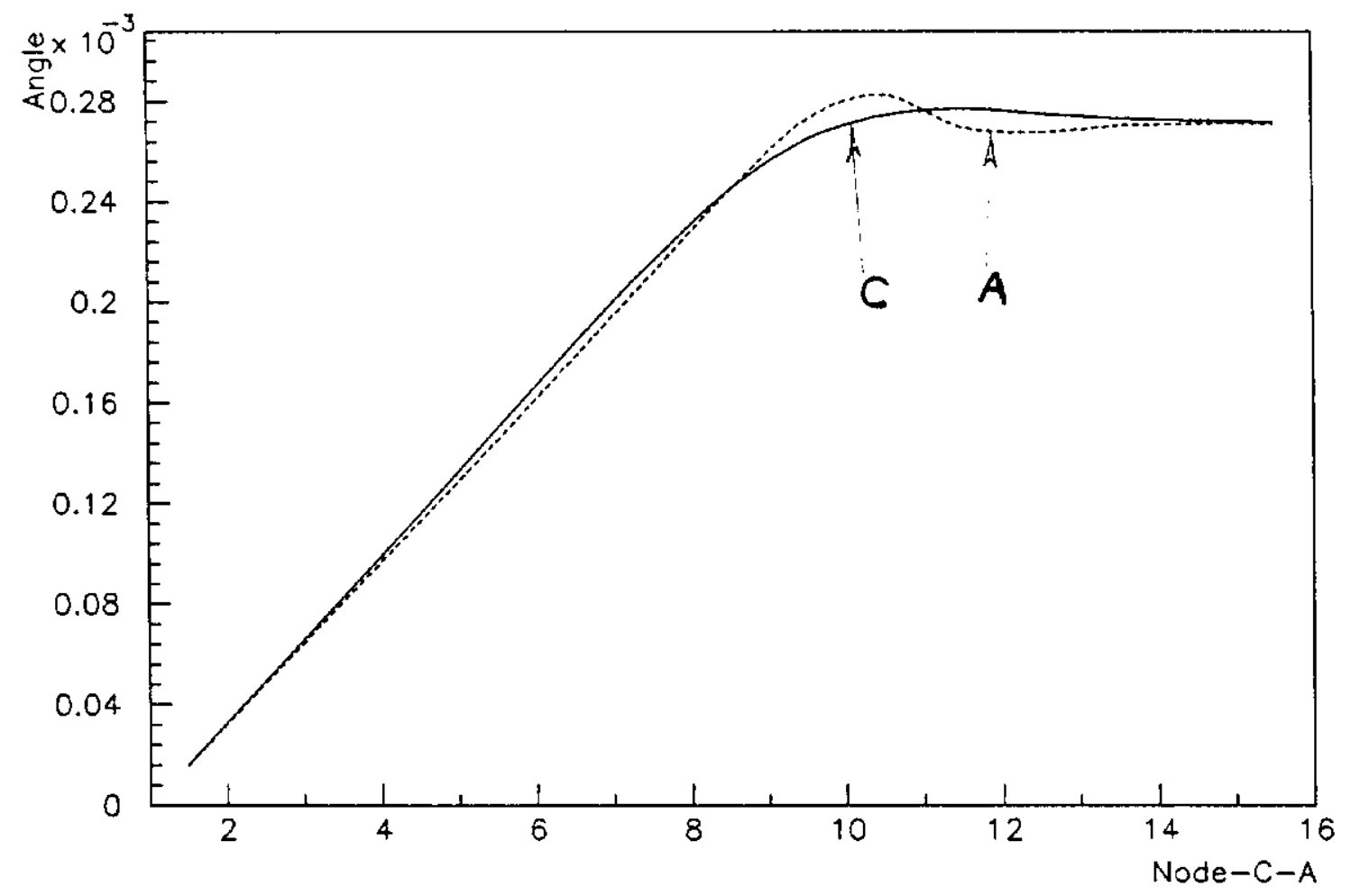

Fig.11 Bend angles at $A, C$ (Bare crystal) 
ANSYS $4.4 \mathrm{~A}$

DEC 141992

$9: 40: 04$

PLOT NO.

POST1 STRESS

STEP $=1$

ITER $=1$

SY (AVG)

CSYS $=11$

DMX $=0.002986$

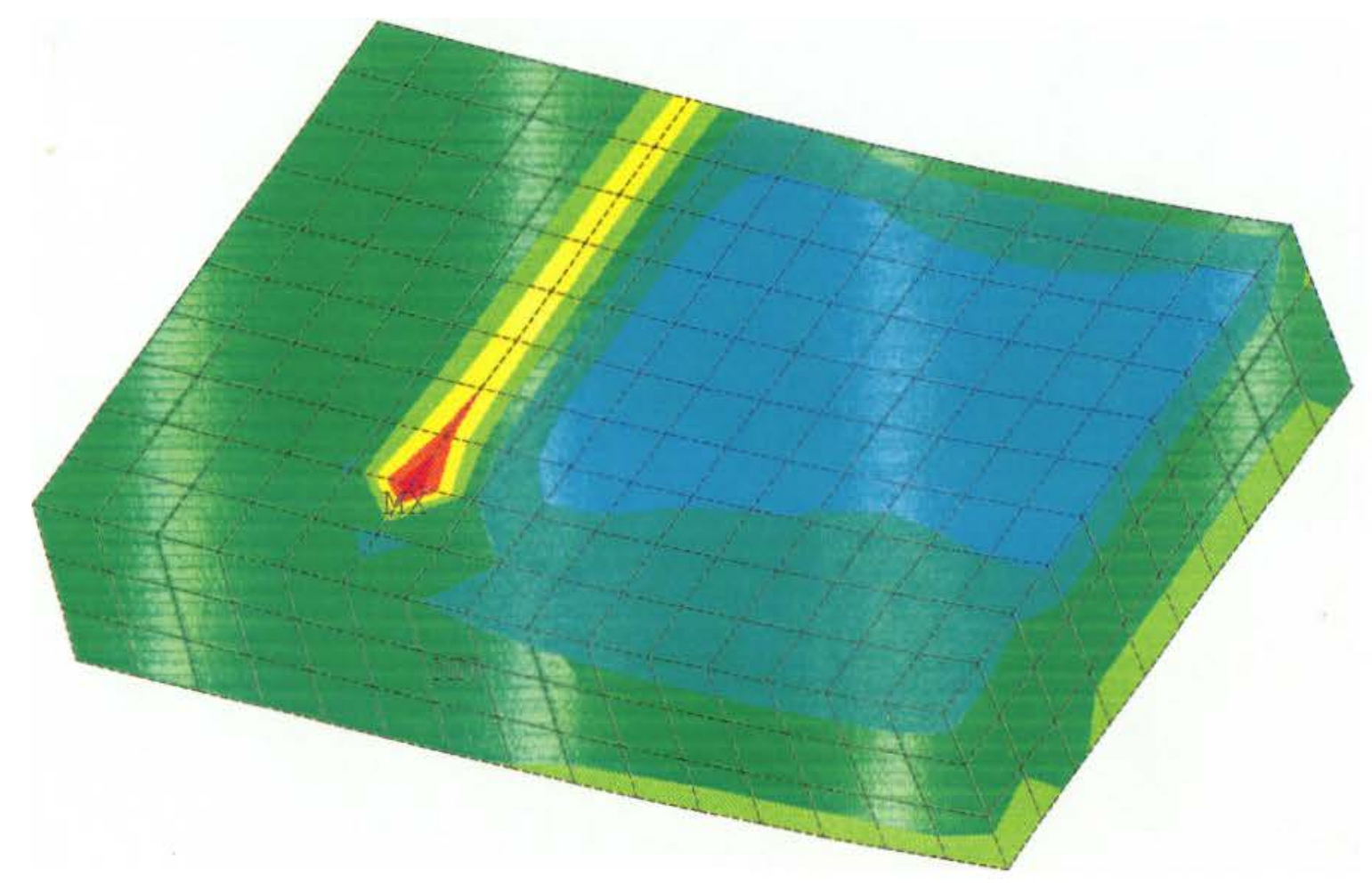

SMN $=-3.574$

SMNB $=-5.459$

$\mathrm{SMX}=3.625$

$\mathrm{SMXB}=5.483$

$\begin{aligned} & \mathrm{XV}=1 \\ & \mathrm{YV}=2 \\ & \mathrm{ZV}=-3 \\ & \mathrm{DIST}=12.225 \\ & \mathrm{XF}=-0.392354 \\ & \mathrm{YF}=7.463 \\ & \mathrm{ZF}=5.258 \\ & \text { ANGZ }=90 \\ & \mathrm{CENTROID} \mathrm{HIDDEN}-3.574 \\ &-2.775 \\ &-1.975 \\ &-1.175 \\ &-0.374829 \\ & 1.225 \\ & 2.025 \\ & 2.825 \\ & 3.625\end{aligned}$



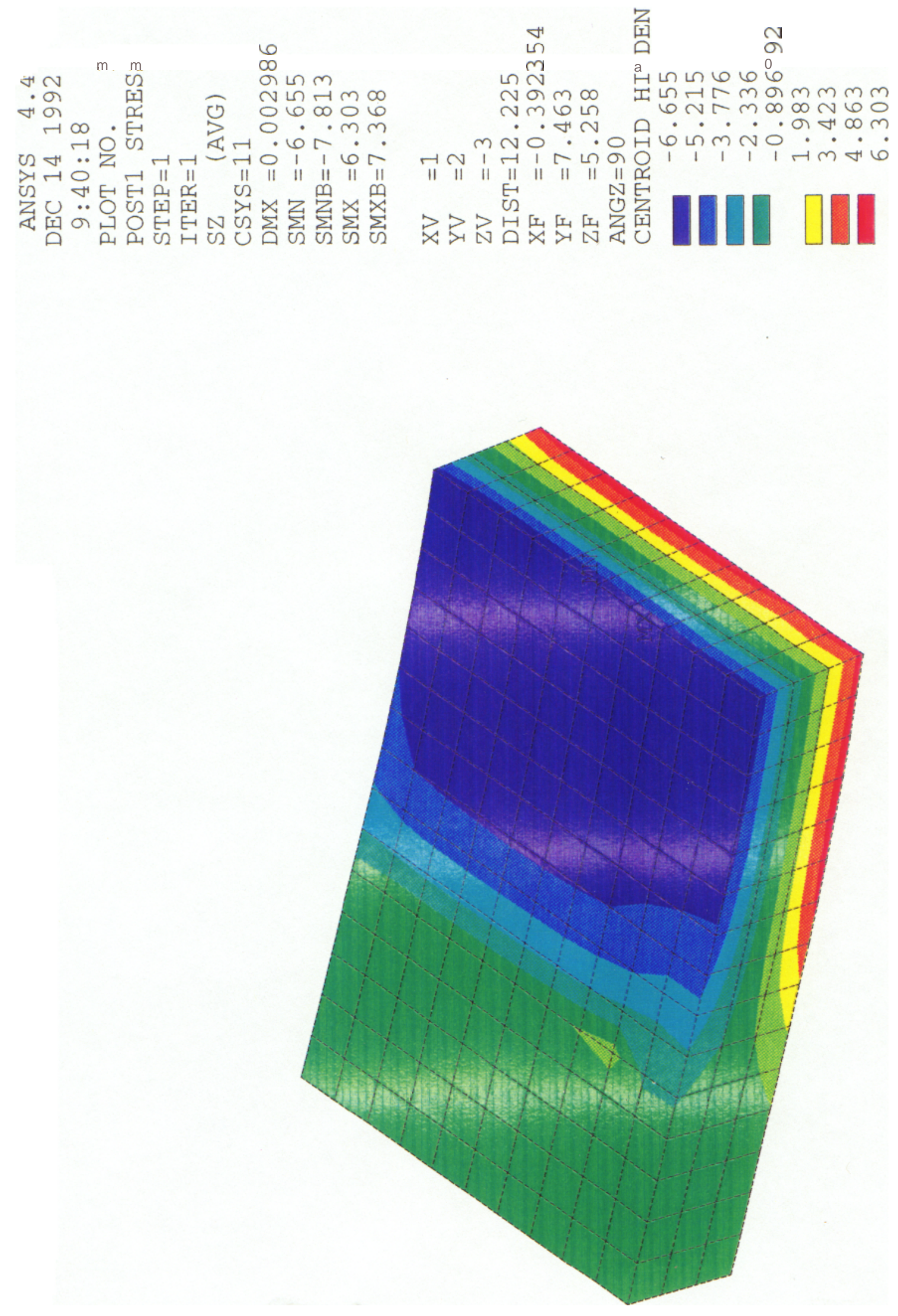

స్త్ర 


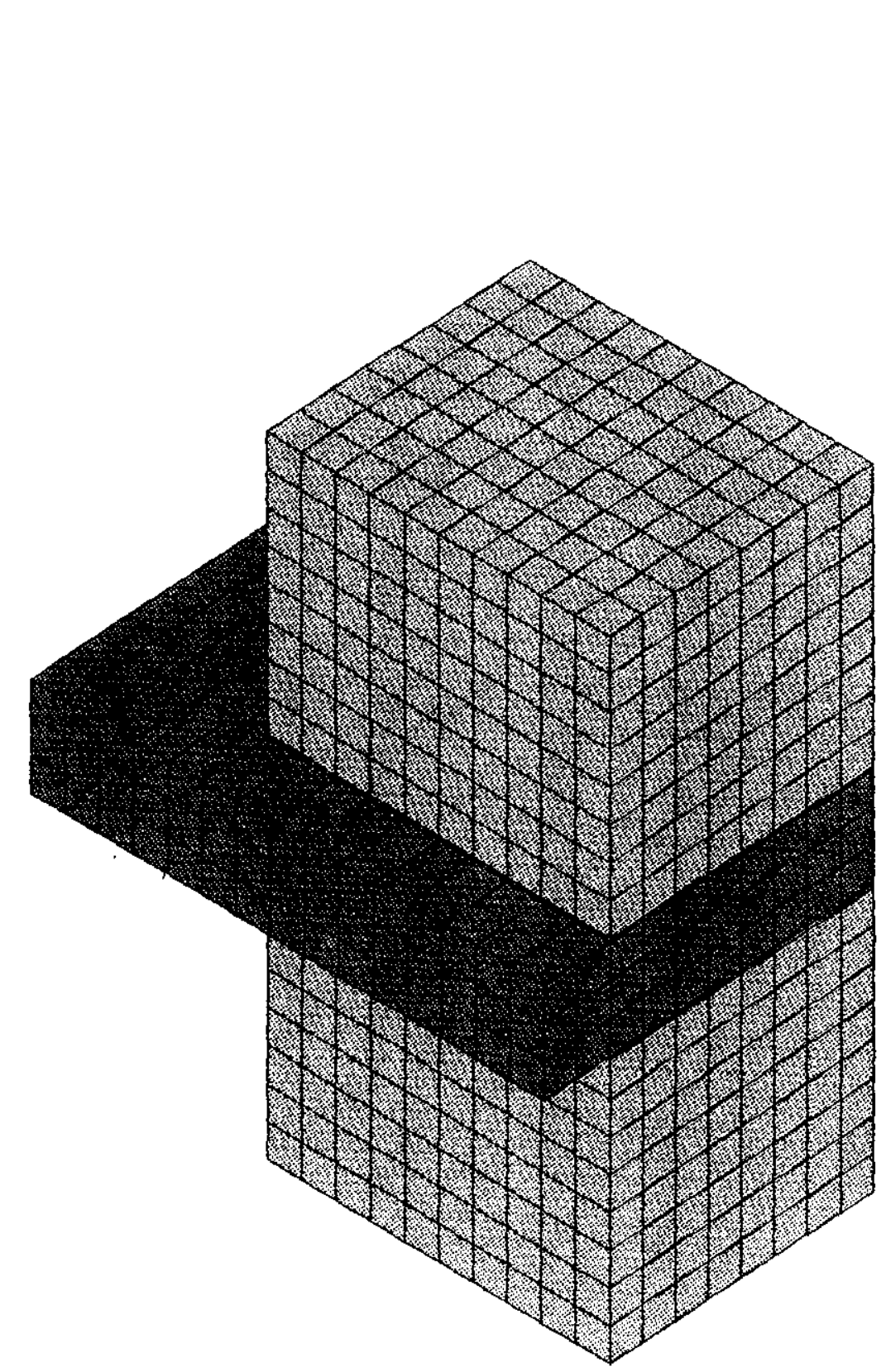

ANSYS 4.4.

JAN 111993

$11: 15: 39$

PLOT NO. 3

POST 1 ELEMENTS

TYPE NUM

$$
\begin{aligned}
& \mathrm{XV}=1 \\
& \mathrm{YV}=2 \\
& \mathrm{ZV}=-3 \\
& \mathrm{DIST}=17.183 \\
& \mathrm{XF}=-0.07884 \\
& \mathrm{YF}=5.736 \\
& \mathrm{ZF}=3.216 \\
& \mathrm{ANGZ}=70 \\
& \text { CENTROID HIDDEN }
\end{aligned}
$$

Fig.14 Crystal between aluminum punches 


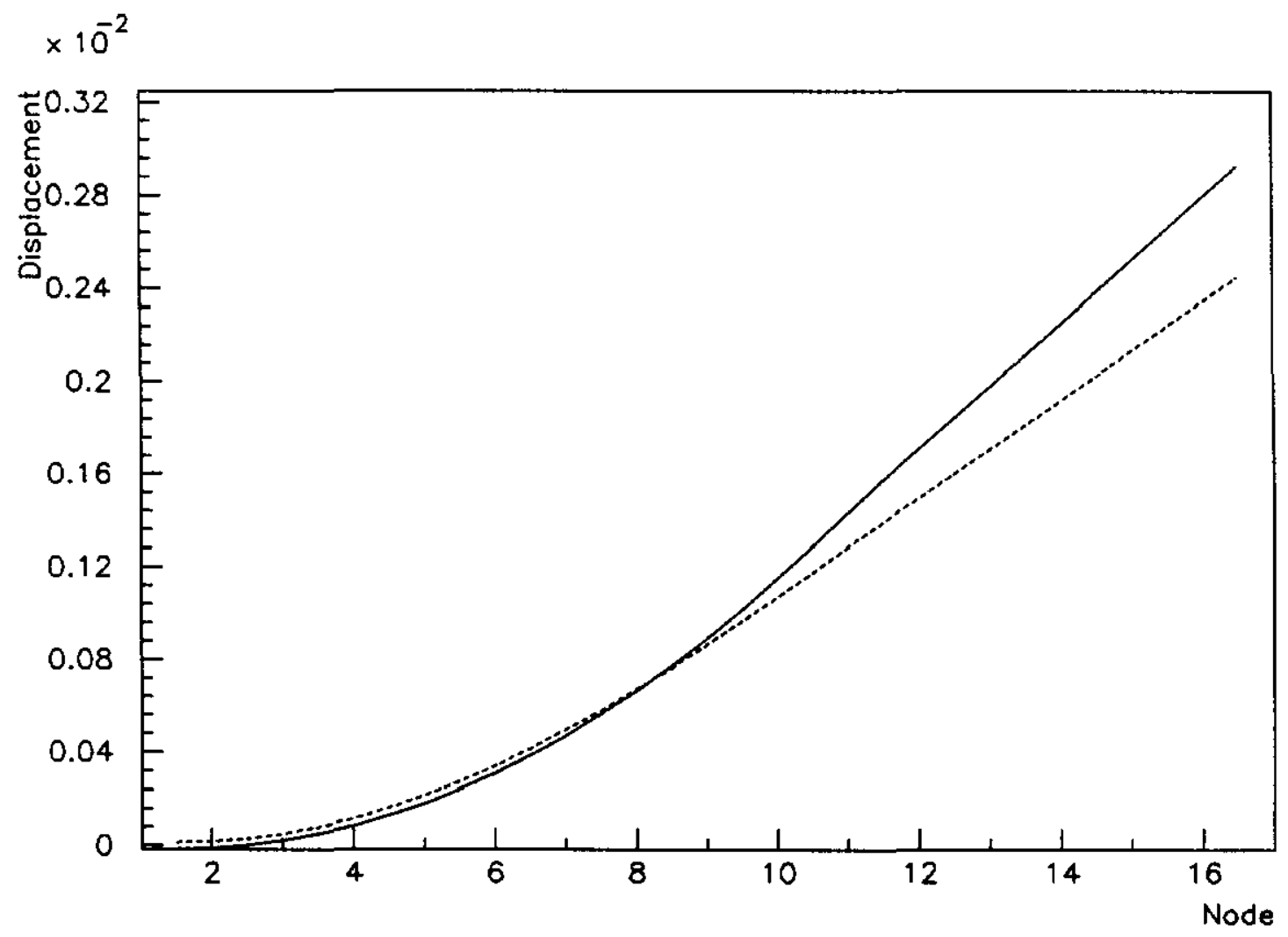

Fig.15 Displacements for bare crystal and crystal between punches 


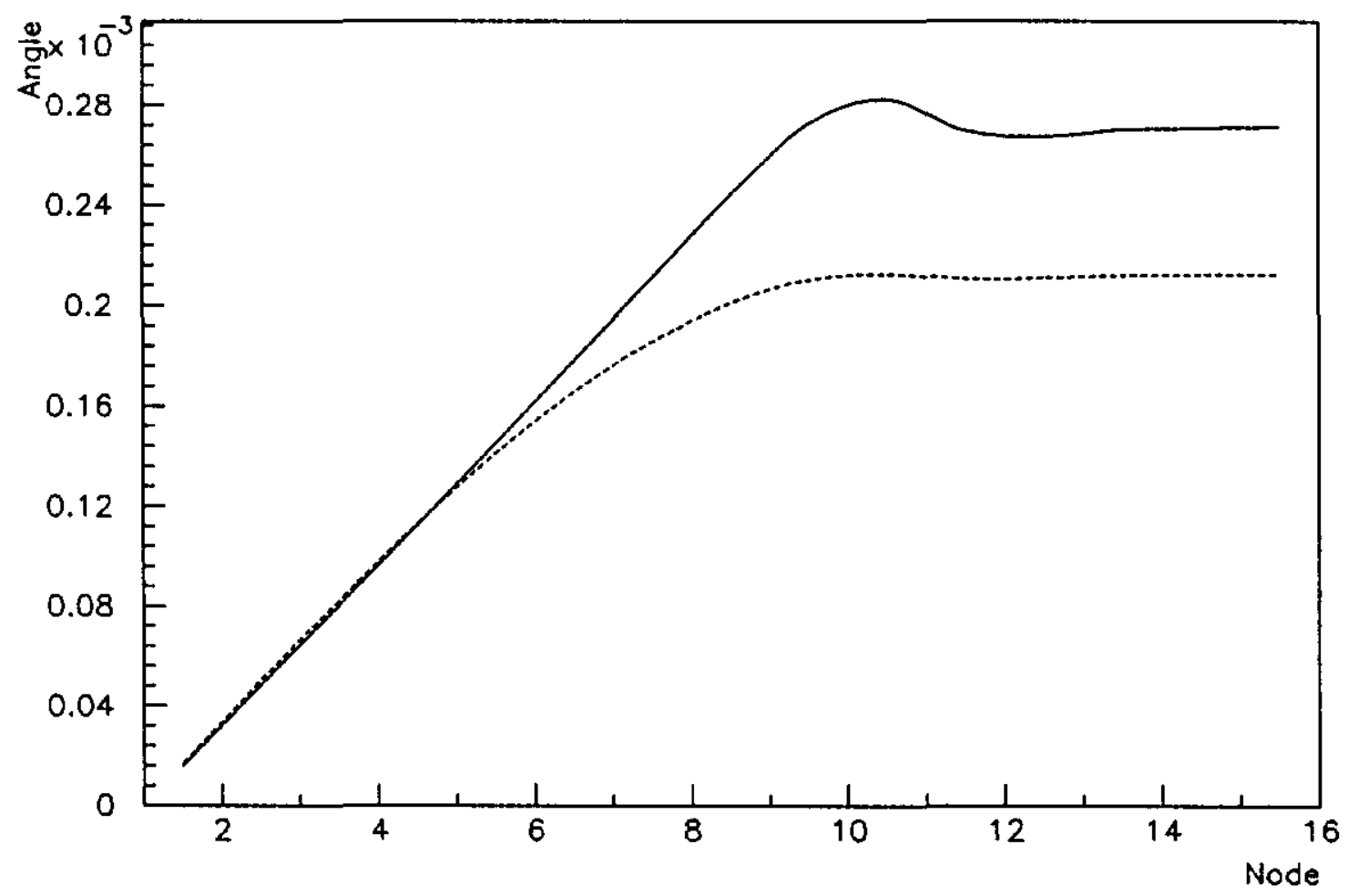

Fig.16 bend angles for bare crystal and crystal between punches 


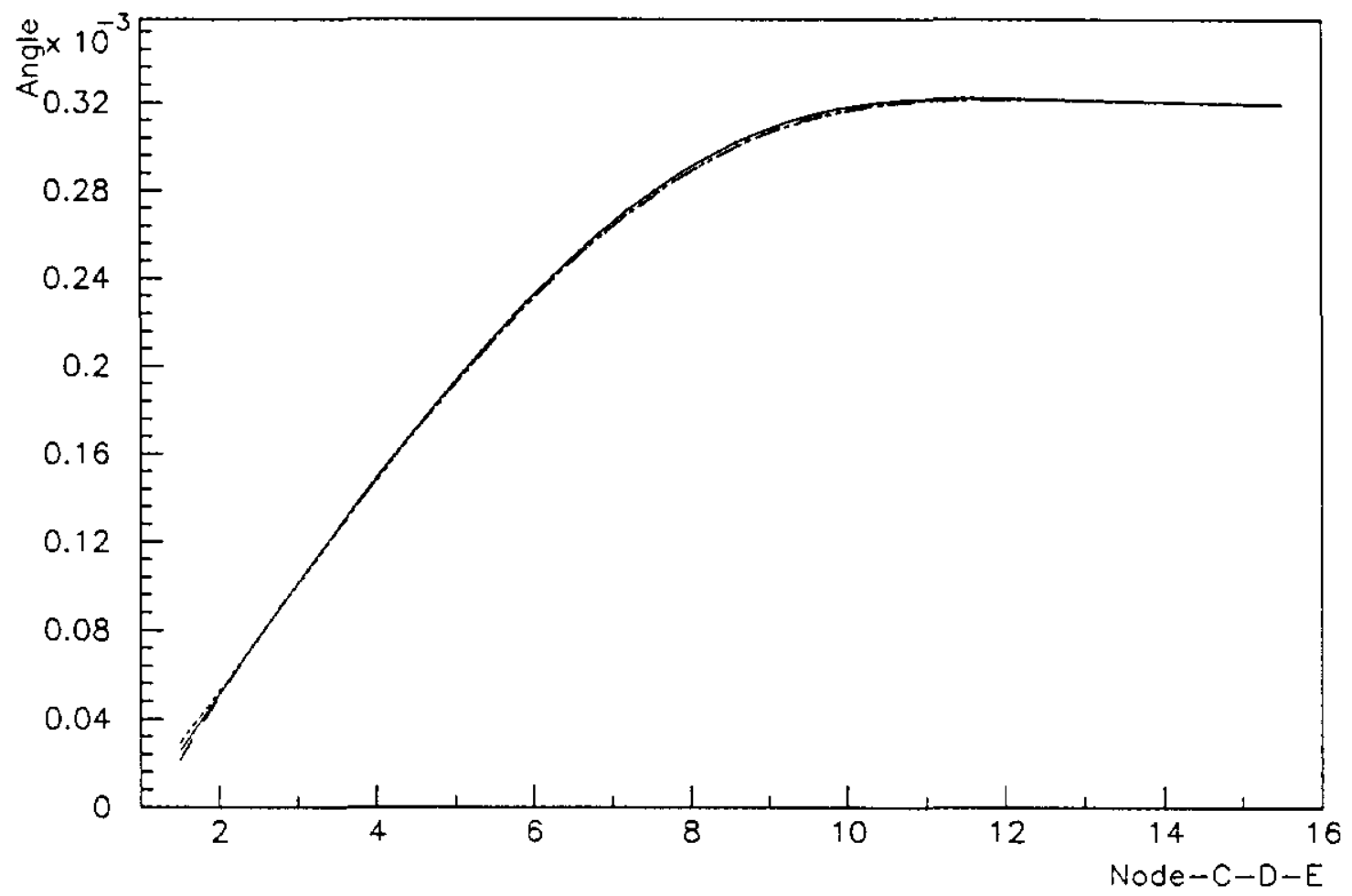

Fig.17 Bend angles at $C, D, E$ (exaggerated punches) 


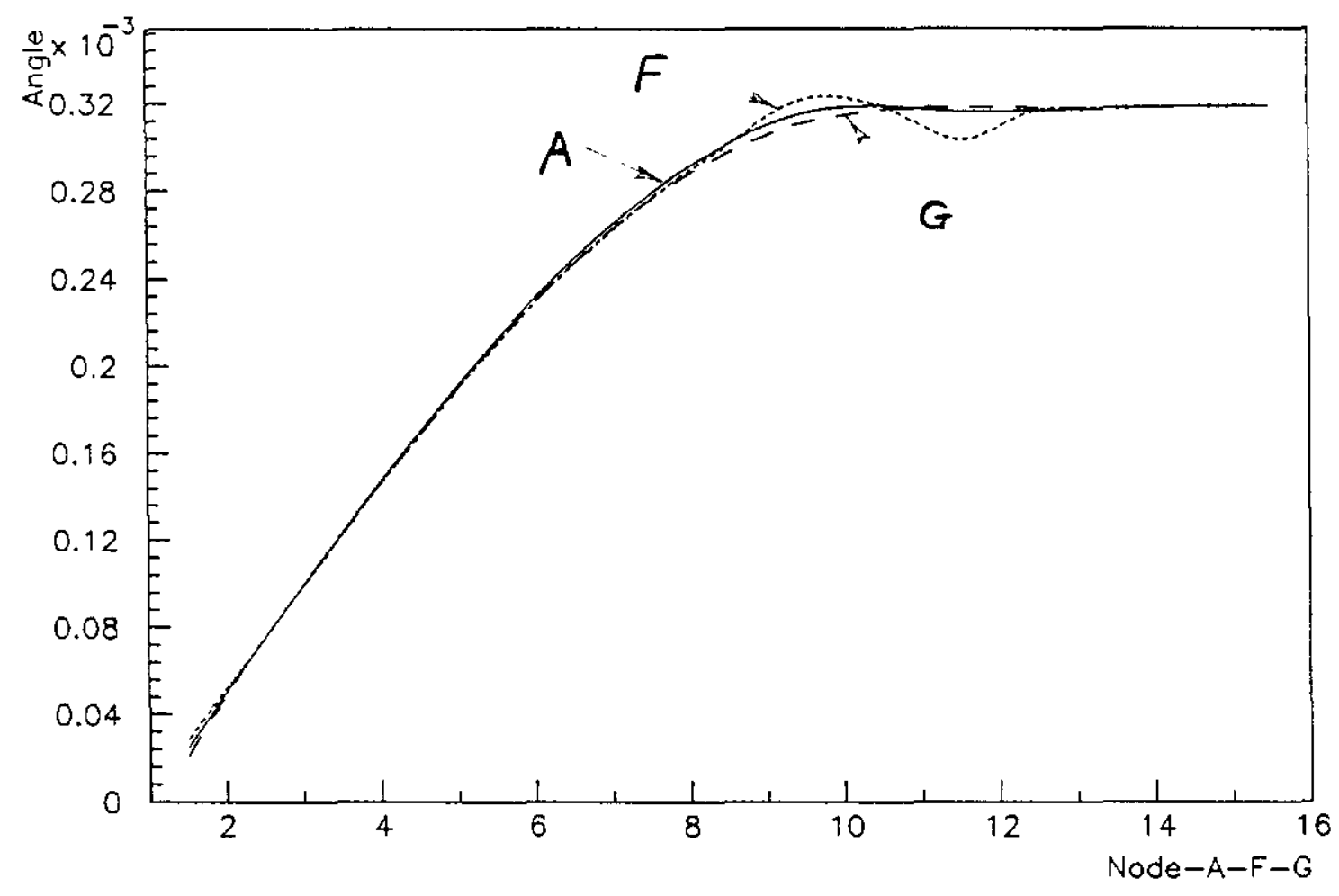

Fig.18 Bend angles at $A, F, G$ (exaggerated punches) 


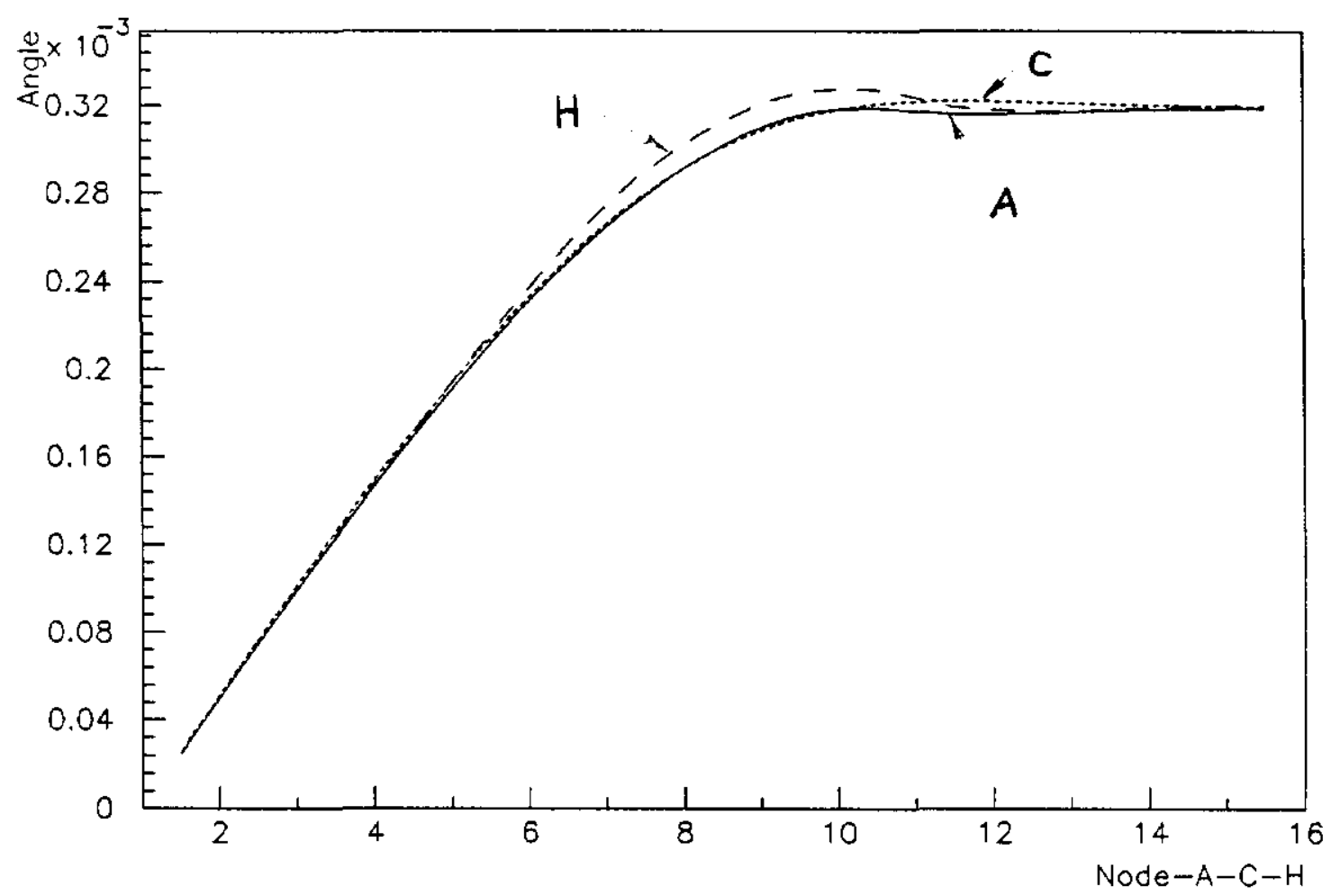

Fig.19 Bend angles at $A, C, H$ (exaggerated punches) 


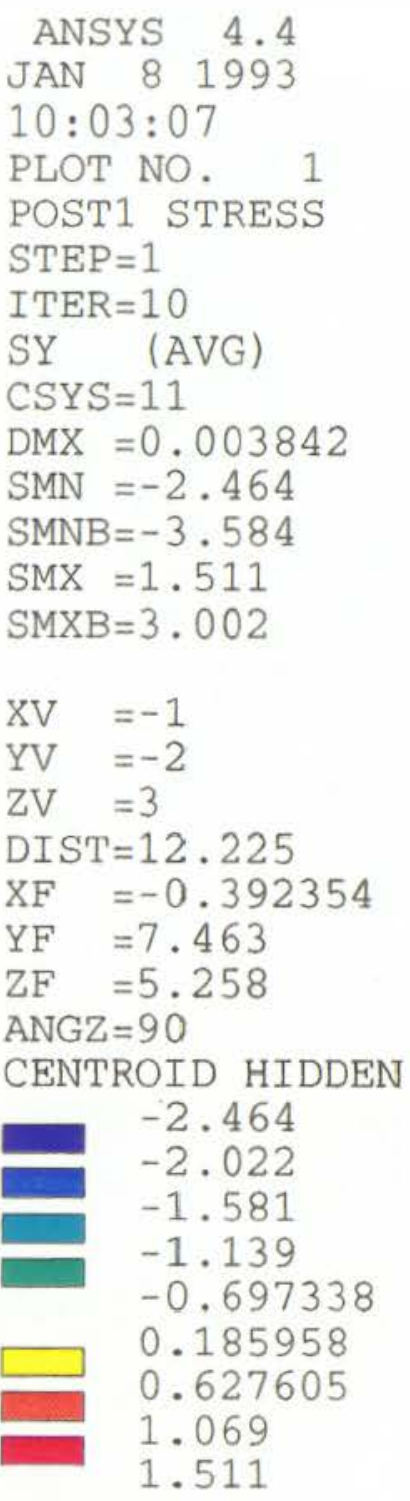

Fig.20 Stress $\sigma_{y}$ (Shown is the bottom surface) 


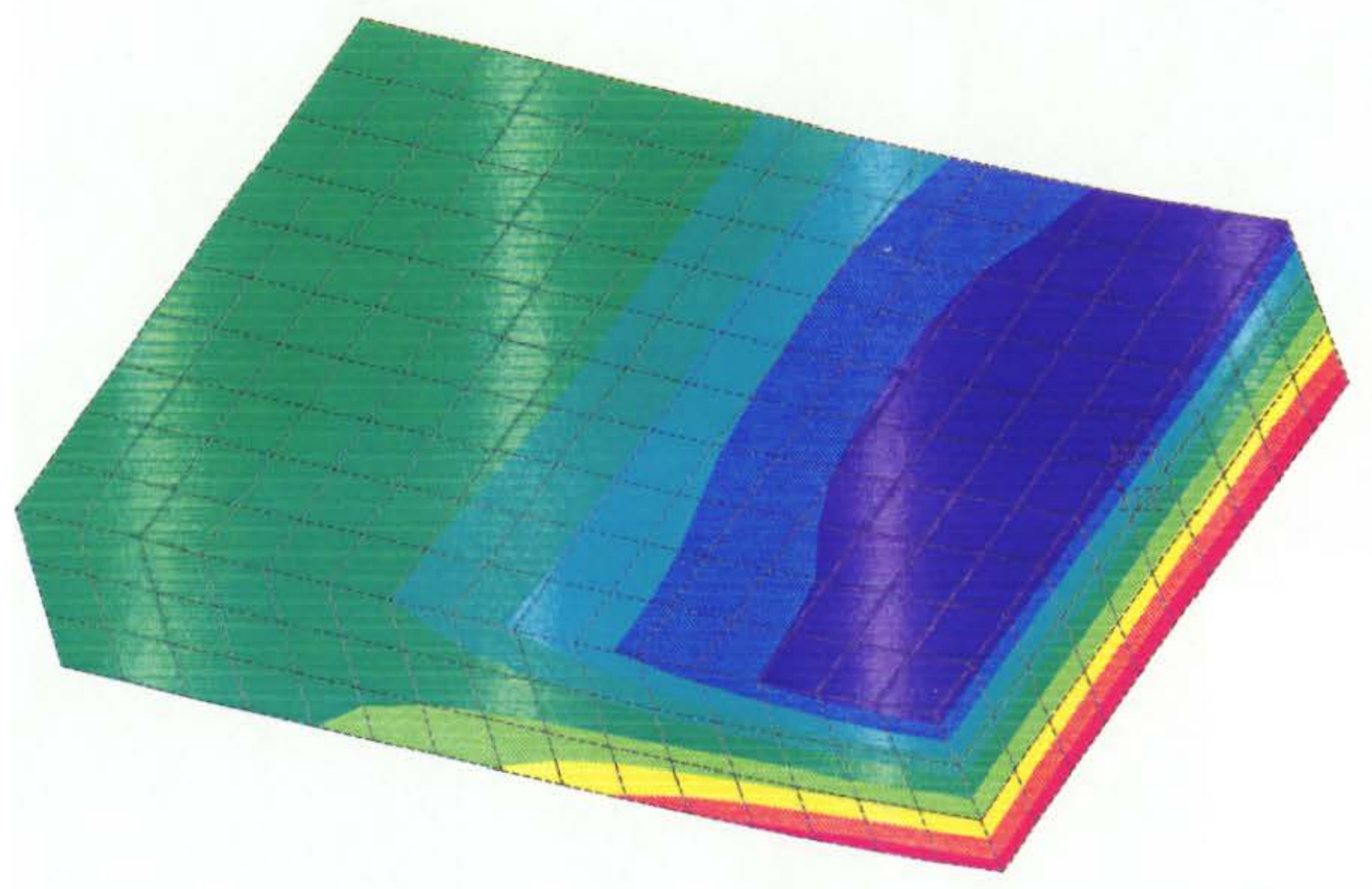

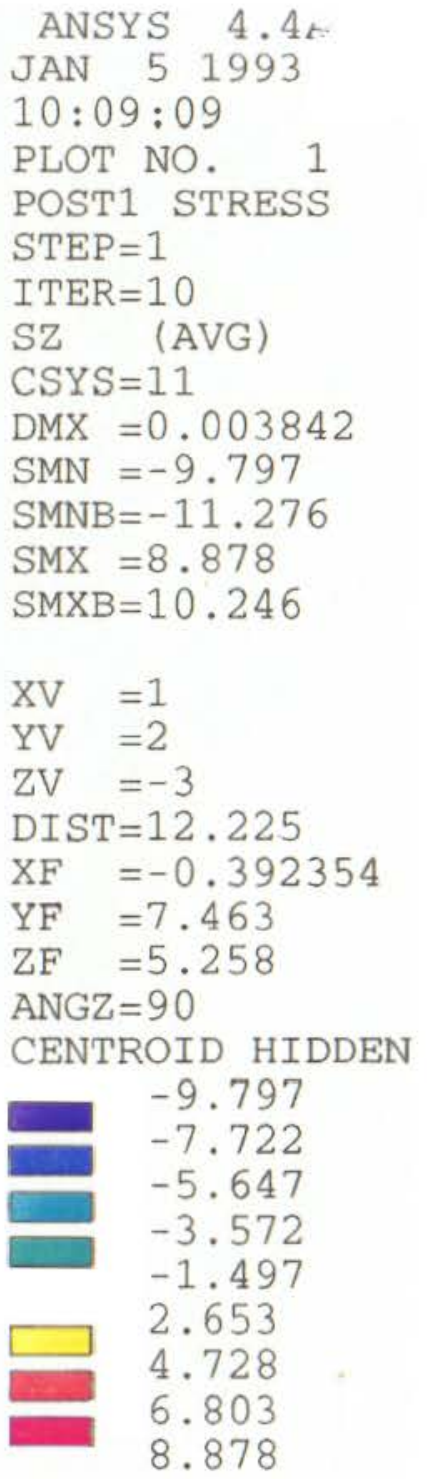

Fig.21 Stress $\sigma_{z}$ 